EDTTOR'S Note:

The following is a guest article prepared by Professor David C. Rowan, who served as a visiting scholar with this bank from September to December 1968. Since 1960 he has been Professor of Economics at the University of Southampton, and also has served as Editor of the Bankers' Magazine. Previously, he was Professor and Dean of the Commerce Faculty at the University of New South Wales, Sydney, Australia, and also taught at the Universities of Melbotrne and Bristol. He is the author of numerous articles dealing primarily with subjects in monetary and international economics.

Professor Rowan's views do not necessarily represent those of the Federal Reserve Bank of St. Lotis or of the Federal Reserve System.

\title{
Towards A Rational Exchange Policy: Some Reflections on the British Experience
}

T

HIS PAPER is deliberately subtitled "Some Reflections ..." to emphasize that it does not aim at providing either a detailed account of the events which led up to devaluation or a full review of Britain's external problem. What it presents is an attempt to derive some lessons of lasting benefit from the failure of British external policy, and in particular, British exchange policy during the Sixties, and from the concurrent, less recognized, failure of the world's international monetary authorities.

These reflections are organized under three principal headings:

(1) the consistency of British exchange policy;

(2) the inadequacy of British exchange policy;

(3) the general applicability of British experience.

Together these topics amount to a single theme - the tendency for most national economic policymakers to neglect economic theory and, a consequence which is at least professionally gratifying, the distressing results of this neglect.

\section{The Consistency of British Exchange Policy}

It is a commonplace that the objectives of British economic policy are to achieve, at a level of capacity utilization which corresponds to "full employment," an "acceptable" rate of growth in real Gross Domestic Product (GDP), usually put at between 3 and 4 per cent per year. Moreover, though the definitions of "full employment" and "acceptable growth" differ, as do the relative importance attached to these objectives and price stability, these aims are shared by most developed countries.

It is equally a commonplace that in Britain, as in other countries, these aims must be pursued subject to a balance-of-payments constraint, and that in $\mathrm{Bri}$ tain this constraint has repeatedly imposed checks to growth because of the emergence of severe balanceof-payments deficits.

Scarcely less familiar is the proposition that an observed deficit in the balance on current and longterm capital accounts reflects three conceptually distinct elements: the first of these is the long-run or secular position of current and long-term capital accounts which we shall call the "fundamental balance"; the second is the cyclical position; the third is a "catch-all" which takes account of such random factors as strikes, climatic disturbances and political uncertainties. The second and third elements we shall call short run. In addition, of course, the observed balance may reflect short-term capital movements arising either from interest rate differentials, the incidence of random factors, or from speculative flows based upon private assessments of the fundamental balance on current account.

In this paper we shall define the fundamental balance as the balance of payments on current and longterm capital accounts which would exist if the country was growing (in terms of real GDP) at its acceptable rate, and if it was maintaining continuously a level of capacity utilization corresponding to full employment. 
Clearly, provided both conditions are met, the fundamental balance will be functionally related to the exchange rate. The exchange rate which would give a fundamental balance of zero can be defined as the "equilibrium rate of exchange." Rates of exchange which do not satisfy this condition are, by definition, rates which involve "fundamental disequilibria,"

Given this framework, we shall now argue that the consistency of British exchange policy in the Sixties with that of the Twenties lies in the fact that, in both periods, the authorities sought to maintain a disequilibrium parity even though to do so involved the sacrifice of both growth and employment.

It is worth noting that this argument entails two propositions. The first is that the pound rate of $\$ 2.80$ was incompatible with fundamental equilibrium during the period $1960-67$ and thus involved a fundamental disequilibrium. The second is that the existence of this fundamental disequilibrium was demonstrable. We shall return to these issues later.

Consider the period 1925-31. In 1925 Britain returned to the gold standard at the pound rate of $\$ 4.86$. At the time the free market rate, at $\&=\$ 4.40$, was about 10 per cent lower. Insofar as the chosen rate was not compatible with a fundamental balance of zero, that is, with fundamental equilibrium, domestic prices and costs had to be forced down to adjust to the new parity. The costs of the attempt to do this, in the face of considerable price-wage rigidity, were industrial strife, unemployment, lost output and the souring of industrial relations to a degree which is, even now, probably a significant factor in Britain's economic situation. In practice, despite severe deflation, adjustment was slow and still incomplete when the gold standard was abandoned in 1931.

The significance of this period is that it was an instance, and with the benefit of hindsight, a peculiarly glaring one, of an attempt by the British authorities to force domestic economic conditions to adjust to an exchange rate; or, what amounts to the same thing, it was a refusal by the authorities to admit the inappropriateness of the selected parity. Because political constraints now limit the extent of deflation, the costs of essentially the same refusal in the Sixties have been less severe. The British authorities again struggled to maintain the existing disequilibrium rate of $\$ 2.80$ and deliberately chose to accept avoidably long periods of relative stagnation and relatively high unemployment.

In both 1931 and 1967 the disequilibrium parities which the British authorities sought to maintain were abandoned. It is doubtful, however, whether these devaluations, when they came, reflected a belated and possibly reluctant recognition that the ruling rate was not an equilibrium rate and thus required modification. Even in 1967, when additional international support for sterling was available, it seems more reasonable to believe that the British authorities recognized that the 1967 crisis, if overcome, would simply be followed by others; in short, that the probability of recurrent speculative attacks and short-term outflows made devaluation inevitable. Thus, the devaluations were not autonomous acts of policy. They were seen by the authorities largely as defeats and, indeed, not infrequently described as such. Our interpretation of the evidence of 1925-31 and 1959-67 therefore suggests that a planned adjustment of the sterling rate - in order to eliminate a fundamental disequilibrium - is virtually unthinkable.

The reluctance to regard the rate of exchange as a discretionary policy variable, and the consequential readiness to try to adjust domestic conditions to the given rate, probably have two origins. The first and presumably less important origin is some memory of the advantages of following the gold standard game. The second is a misreading of the experience of the Thirties.

In the period 1925.31 , British policy was based upon a coherent version of the classical gold standard theory. By 1931, this theory was widely recognized as unhelpful. Unfortunately no systematic theory immediately took its place and the British monetary authorities, like the monetary authorities elsewhere, had to face the stresses of the Thirties with no coherent macroeconomic theory to guide them. One result was that the decade prior to World War II was one of competitive devaluations. ${ }^{1}$ These were either "beggar-my-neighbor" attempts to export unemployment, or retaliation to such attempts. The experience of this decade, including the competitive devaluations, their accompanying uncertainties and "hot" money flows, and the extension of exchange control, reinforced the British (and other) monetary authorities' instinctive preference for fixed rates of exchange. Indeed it is arguable that they were interpreted to mean that discretionary exchange adjustments, or the adoption of floating rates, were invitations to monetary chaos, and hence that fixed exchange rates were the path of wisdom.

As we shall see, this interpretation was erroneous. Nevertheless it had a profound effect upon the post-

IR. Nurkse, International Currency Experience (League of $\mathrm{Na}-$ tions, 1944), pp, 210 and 211. 
World War II monetary arrangements agreed to at Bretton Woods, and a no less profound, but considerably more harmful, effect upon the way in which the Bretton Woods scheme has been operated.

\section{The Inadequacy of British Exchange Policy}

In a multilateral trading world in which each country is seeking (though admittedly with varying degrees of success and with greater or lesser stringency of definition) to maintain both acceptable growth and full employment, it is clear that the emergence of any fundamental disequilibrium on external account must either be met by an adjustment of the rate of exchange or by the specification of some alternative method of eliminating the fundamental disequilibrium. This obvious proposition, which has been sadly neglected, is clearly implied in the following quotation from a speech by Lord Keynes to the House of Lords.

In May 1943, speaking on the subject of international currency plans, Keynes said;

The exchange value of sterling cannot remain constant in terms of other currencies, unless our efficiency-wages, and those other costs of production which depend on our social policy, are keeping strictly in step with the corresponding costs in other countries. And, obviously, to that we cannot pledge ourselves. I hope Your Lordships will believe me when I say that there are few people less likely than I not to be on the lookout against this danger. The British proposals (for the IMF) nowhere envisage exchange rigidity. They provide that changes of more than a certain amount must not be made unless the actual state of trade demonstrates that they are required, and they provide further that changes, when made, must be made by agreement. Exchange rates necessarily affect two parities equally. Changes, therefore, should not be made by unilateral action ...."2

A year later, speaking in defense of the International Monetary Fund, Keynes argued:

We are determined that, in future, the external value of sterling shall conform to its internal value as set by our own domestic policies, and not the other way round. Secondly, we intend to retain control of our domestic rate of interest, so that we can keep it as low as suits our own purposes, without interference from the ebb and flow of international capital movements or flights of hot money. Thirdly, whilst we intend to prevent inftation at home, we will not accept

?J. M. Keynes, House of Lords, May 18, 1943. deflation at the dictate of influences from outside. In other words, we abjure the instruments of bank rate and credit contraction operating through the increase of unemployment as a means of forcing our domestic economy into line with external factors. ${ }^{3}$

In both passages Keynes' argument is that, in the event of a conflict between the maintenance of a given parity and domestic policy objectives, it is the exchange rate and not domestic conditions which must be adjusted. Moreover, from the emphasis which Keynes gave to the issue, it is clear that he did not regard a conflict between domestic and external objectives as unlikely. He thus, by implication at least, denied the existence of any quasi-automatic mechanism tending to eliminate fundamental disequilibrium in the balance of payments. In addition, it could be argued with little exaggeration that he largely foresaw the British post-war extemal problem. Finally, Keynes saw that the experience of the Thirties provided a case against unilateral exchange changes but not against exchange changes.

By contrast, as we have seen, the British authorities have been markedly reluctant to adjust the exchange rate. Thus, even if they did not reject the theory underlying Keynes' policy recommendations, ${ }^{4}$ their policies during the last decade, like their policies from 1925-31, implied such a rejection. Logically this can only suggest that they were either unconvinced of the existence of a fundamental disequilibrium or able to specify an alternative adjustment mechanism not requiring changes in rates.

It is difficult to trace in British official publications any clear admission of the existence of a fundamental disequilibrium or statement of the mechanism upon which the British authorities were relying for balanceof-payments adjustments in the presence of a fixed rate of exchange and a relatively stringent full-employment constraint. However, it is possible to dis. cern, notably in the publications of the N.E.D.C., ${ }^{5}$ a suggestion that the existence of a fundamental disequilibrium was implicitly accepted as well as the elements of two theories of adjustment.

\footnotetext{
3J. M. Keyres, House of Lords, May 23, 1944.
}

4It is worth noting that, in his last article, Keynes took a stronger position, arguing that the "classical medicine" could not be relied upon and that "we need quicker and less painful aids of which exchange yariation and over-all import con" trol are the most important." See I. M. Keynes, "The Balance of Payments of the United States," Economic Journal, June 1946.

जN.E.D.C. denotes the National Economic Development Council, an official research agency of the British government. 
On the first issue, it is surely significant that the N.E.D.C., after calculating that the 4 per cent "target" rate of growth in GDP required a 5 per cent rate of growth in exports, argued that this required ". . a a small relative fall in the prices of British manufactures." In later publications by the same body the same diagnosis recurs with greater emphasis. ${ }^{7}$ Thus the publication Export Trends gives considerable emphasis to the role of relative costs and prices in influencing export performance, sets out a short and generally favorable interpretation of the French devaluation of 1957, and concludes that the required growth in exports might "... not be forthcoming unless the prices of manufactures on the home market fall relatively to foreign export prices." ${ }^{\text {s }}$

It thus seems reasonable to interpret these documents as guardedly admitting the existence of a funm damental disequilibrium. They are, however, considerably less easy to interpret on the issue of the mechanism of adjustment.

Two interpretations are permissible of these N.E.D.C. documents. The first is that the N.E.D.C., in its emphasis on relative price adjustments, was coming as close to the open advocacy of devaluation as its official position permitted. The second is that, though probably favoring an exchange adjustment, the N.E.D.C. was, as a second-best alternative, prepared to support the official line which seems to have been founded on a particular version of what might be called the "neo-classical first difference theory."

At its crudest, the classical theory envisages the downward adjustment of the level of prices in deficit countries through deflation and, though less firmly, the upward adjustment of prices in surplus countries. In some versions this was seen as the quasi-automatic outcome of specie flows. The fundamental hypotheses of this theory were the absence of both wage-price rigidity and official neutralization policies. After the experience of the Twenties and Thirties, neither hypothesis was any longer acceptable.

The classical theory thus visualized the adjustment process as modifying price and cost levels. The new version accepts that price and cost levels are inflexible downwards. However, since costs and prices are generally rising throughout the world, it replaced price and cost levels by their rates of change. On this

NN.E.D.C., Growth of the United Kingdom Economy to 1966 (Her Majesty's Stationery Office [H.M.S.O.], 1963), paragraph 280 .

7N.E.D.C. Conditions Favourable to Faster Grouth (H.M.S.O., 1963), Section D and F and paragraphs 201 and 211.

8N.E.D.C., Export Trends (H.M.S.O., 1963), paragraphs 27-58. basis the adjustment process required the discretionary reduction of the rate of increase in British costs below the rates of increase ruling in her principal competitors. Provided policy could achieve this, then, after a sufficient period of time, the necessary adjustment would be brought about.

\section{Lmplonment Whe Traderoy}

One of the principal conclusions of empirical research into the interrelationship between price and cost changes in the United Kingdom is that a functional relationship exists between the percentage of the work force unemployed and the rate of change of money wages. The relationship is usually called the "Phillips curve" and is to be interpreted as a labor market adjustment curve. Though the interpretation of this curve in the United Kingdom is still to some extent a matter of dispute, its existence seems to command general acceptance." The neo-classical first difference mechanism, which specifies discretionary operation on the rate of change of money wages, thus requires interpretation in terms of this relationship. In practice there seem to be three policy variants:

(1) the "excess-capacity" view usually associated with the name of Professor F. W. Paish;

(2) the "incomes-policy" view; and

(3) the view of which seeks to combine (1) and (2).

The basic assumption of the excess-capacity view is that the Phillips curve is a stable relationship which can be relied upon as a means of formulating policy quantitatively. Given this, the objective is to operate the economy at an average percentage of unemployment (usually estimated at $2-2^{1 / 2}$ per cent) which will generate (assuming the rate of productivity increase to be invariant) the desired rate of change in wage costs per unit of output.

The basic assumption of the incomes-policy view is that the Phillips curve is not stable, has shifted, and can be shifted again by an appropriate incomes policy, so that, for a given percentage of unemployment, a lower rate of increase in wage costs will result. ${ }^{10}$

The literature on this relationship is extensive. Fxcellent general surveys and bibliographies are to be found in: J. $C$. $R$. Dow, The Management of the British Economy: 1945-1960 (Cambridge: Cambridge University Press, 1964), chapter XIII; R. E. Canes et al, Britain's Economic Prospects (Washington: The Brookings Institution, 1968), chapter 3 ; and also see George McKenzie, "Intermational Monetary Reform and the 'Crawling Peg'" in the February 1969 issue of this Review.

10 Dow, pp. 402 and 403. 
The combination of the two views accepts that the Phillips curve is shiftable but appears to believe that the essentially political exercise of an incomes policy would have a better prospect of success if the unemployment percentage was kept, on average, between 2-21/2 per cent rather than (say) between 11/2-2 per cent.

Of these three views, only the first, even on its own assumptions, is readily quantifiable, for the other two necessarily involve shifts in the Phillips curve and thus the specification of the severity of incomes policy. Moreover, though the incomes-policy view does not, the other two involve costs in terms of additional unemployment.

There is little systematic evidence of the quantitative impact of incomes policy in the United Kingdom. What evidence there is suggests that in practice it has been, in the short run, an unreliable device. ${ }^{11}$ Hence the two relevant policy variants are probably the excess-capacity view and the combination view, and a choice of these and an exchange adjustment can be made rationally only on quantitative grounds. Any attempt to assess the combination view in quantitative terms must be highly tentative, for the meaning of an incomes policy is far from clear, and considerable uncertainty attaches to its performance.

By contrast the mechanism of adjustment through exchange variation has been extensively studied by economists. The theory of adjustment is relatively well understood and there is a considerable body of quantitative information. Admittedly much of this is imperfect, and estimates of the relevant elasticities vary. Nevertheless, there is more reliable and relevant quantitative information about exchange-rate adjustment than about the policy mix actually selected by the British authorities, which was a combination of "some" additional unemployment (excess capacity) and "some" incomes policy, or what we have called the combination view.

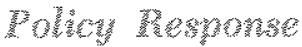

In retrospect, therefore, it seems that from 1960 to 1967 the British authorities preferred to base policy upon a loosely specified policy mixture about which little was known quantitatively, rather than upon the extensively studied mechanism of exchange adjustment.

As a result, policy has been basically irrational in the sense that it has been based not upon an estimate

\footnotetext{
1 Caves, chapter 3 and also see the National Board for Prices and Incomes, Third General Report (H.M.S.O., July 1968), particularly Appendix A.
}

of the extent of the fundamental disequilibrium and the calculated capacity of the selected policy mix to eliminate it, but on the hope that whatever degree of adjustment, the chosen mixture brought about would prove to be quantitatively adequate. An immediate consequence of this has been that, in practice, British economic policy has been based not upon rational calculations about the state of the fundamental balance, which economics suggest to be the relevant concept, but upon the state of the observed balance in the external accounts. This is not the relevant concept for exchange policy for, in the short run, markets may not be cleared; excess demand may exist at home or abroad; cyclical fluctuations at home and abroad may not be in phase; the flow of goods may be interrupted by industrial disputes, political uncertainty or even climatic disturbance, so that the flow of payments is influenced by these factors as well as by speculation about the existing exchange rate. As a determinant of long-run exchange policy, the observed balance is therefore likely to be a poor and misleading guide. Concentration upon it, and this concentration amounts in the United Kingdom almost to an obsession, inevitably tends to confuse short-run and long-run positions and thus shortrun and long-run policies.

The confusion was particularly marked in the United Kingdom during the Sixties when the state of the observed balance dominated short-run policy regarding the control of demand. Purely temporary and cyclical improvements have been confused with improvements in the fundamental balance. As a result, temporary observed surpluses have encouraged temporary expansions which have led to the emergence of large deficits. And these large deficits have, in their turn, made it necessary to impose further periods of slow growth.

Thus it seems clear that the British authorities' attachment to exchange rigidity, which arose in large measure because of a misinterpretation of the experience of the Thirties, led not only to the rejection of the received "classical" theory of international adjustment, but also to the neglect to specify an alternative adjustment process. As a consequence, attention has been focused upon the observed balance rather than the theoretically relevant fundamental balance and policy has been based upon pseudosolutions.

These criticisms, if valid, require that the theoretically relevant concept of the fundamental balance should be quantifiable. To this issue we must now turn our attention. 


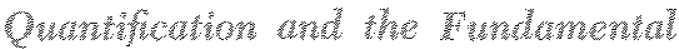 ry}

To calculate the fundamental balance, on the assumption of a given level of capacity utilization and a given target rate of growth, theoretically requires a complete and quantitatively estimated model of the British economy and at least its principal trading partners. The parameters of such a model need to be independent of the problem under examination. No such model exists. Until such a model is complete we can make only a rather crude first approximation to the information we need to formulate a rational exchange policy under a regime of fixed exchange rates.

Where no structural model exists, it remains possible to derive information from forecasting models. Such models are inevitably crude. Their relation to economic theory is not always clear and their parameters are not always readily related to the parameters of a structural model. Nor are they necessarily independent of the problem under investigation. Nevertheless, information to be obtained from a forecasting model provides a useful check on policy and, in particular, on the assumptions underlying British exchange policy. Accordingly, in what follows we present some calculations, derived from an elemen. tary forecasting model, of the fundamental balance on visible trade and current account for the United Kingdom.

The structure of this model is very simple and the load of assumptions it carries is correspondingly heavy. There is no suggestion that it is the best forecasting model which could be constructed. Refinement might or might not be worthwhile. We have not attempted it because the purpose of these estimates here is to suggest orders of magnitude rather than precise numerical values.

We begin by dividing real imports into two components: those which are primarily inputs to the domestic production process and those which are primarily finished goods. This gives us the identity;

$$
I=I_{i}+I_{t}
$$

We seek to explain imports of inputs by three variables, real gross domestic product, the rate of inventory accumulation, and the relative prices of British and overseas goods entering the input classification. Assuming a linear relation this gives:

$$
\text { where } \begin{aligned}
\mathrm{Y} & =\text { real gross domestic product; } \\
\Delta \mathrm{S} & =\text { real investment in inventories; } \\
\mathrm{P}_{\mathrm{h}}, \mathrm{P}_{\mathrm{f}} & =\text { home and foreign materials prices. }
\end{aligned}
$$

For imports of finished goods we postulate a similar function, though in this case we include a dummy variable $\left(Z_{3}\right)$ designed to take account of the liberalization of trade in 1957-58 and the apparently decreasing nonprice competitiveness of British manufacturers. This gives:

$$
I_{\mathrm{f}}=\alpha_{4}+\alpha_{5} \mathrm{Y}+\alpha_{6} \Delta S+\alpha_{7}\left[\frac{P_{\mathrm{hf}}}{\mathrm{P}_{\mathrm{ff}}}\right]+\alpha_{8} \mathrm{Z}_{3}
$$

where $P_{\mathrm{h},}, P_{\mathrm{ff}}=$ home and foreign prices of finished goods;

$$
Z_{3}=\text { proxy for the influences of liberaliza- }
$$
tion and nomprice competitiveness.

Applied to annual data for the years 1953-66, these equations perform surprisingly well, at least in the sense of providing high correlation coefficients and little evidence of serial correlation in the residuals. Moreover, the parameter values are generally significant and the signs are as expected. The results of the regressions, together with the implied marginal propensities and price elasticities, are in Table I.

If these results are accepted as a reasonable basis for forecasting, we can now estimate the "full-employment", "acceptable-growth" import bill by assuming:

1) that full employment is defined by an unemployment percentage of $1.6 \%$;

2) that GDP grows at an acceptable rate of either 3 per cent or 4 per cent; and

3) that the home and foreign prices of materials and finished goods are the actual prices ruling in each year.

To do this we must find some way of estimating the rate of planned investment in inventories. To do this we write:

$$
S^{*}(t)=\lambda Y(t)
$$

where $S^{*}=$ the planned level of stocks, so that

$$
\Delta S^{*}(\mathrm{t})=\lambda[\mathrm{Y}(\mathrm{t})-\mathrm{Y}(\mathrm{t}-1)] .
$$

On this basis, given the regression equations and the observed values of $P_{\varepsilon}$ and $P_{t f}$ for all $t$ years, we can calculate the "fundamental" import bill at current prices.

On the export side we take both the real demand for exports and their prices to be independent of the domestic level of activity and rate of growth. These rather heroic hypotheses allow us to treat export receipts as exogenous with unchanged exchange rates. 


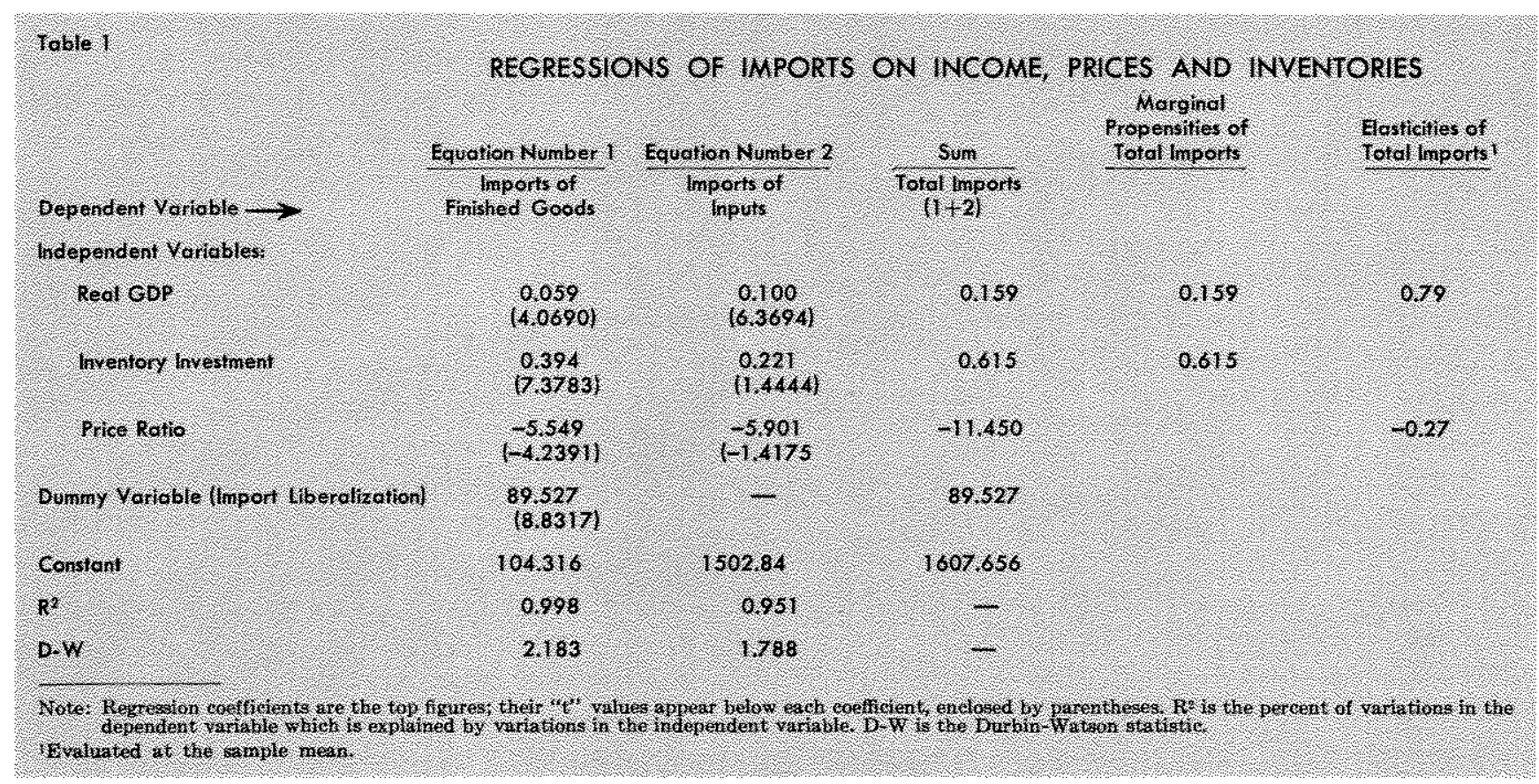

We are thus able to calculate the full-employment, acceptable-growth balance of trade for each year.

We now adjust these figures in two ways. First, we add an estimate of the invisible balance; second, we add an amount, taken to be $\$ 60$ million a year, to allow for a systematic underestimate of current receipts thought to occur in the British accounts. This gives us a figure for the estimated "fundamental current balance."

Finally, we take account of the fact that an appropriate definition of fundamental equilibrium in the British case must make allowance for a "normal" net outflow of long-term capital and the need to provide for some measure of reserve accumulation and/or debt repayment. A figure of $£ 300$ million a year, now probably an underestimate, has, in the past, achieved some degree of official acceptance. ${ }^{12}$ Hence we define the condition of fundamental equilibrium as follows:

Exports (f.o.b.) - Imports (f.o.b.) + Net Invisible Balance $+£ 60$ million $-\& 300$ million $=0$

In Table II we give an estimate of the "fundamental deficits" and the "fundamental current account deficits" for each year from 1953 to 1966 for both assumed "acceptable" growth rates.

\footnotetext{
12Essentially this figure makes little or no allowance for the need to repay the debt arising out of the cumulative deficits of 1964 to 1968 .
}

Obviously the calculations underlying Table II are crude and carry a very heavy load of assumptions. ${ }^{13}$ Three points in particular should be noted.

1) The application of the target surplus of 2300 million to the year before 1959 may somewhat overstate the fundamental deficit for those years.

2) The prices used in the calculation for the early years reflect the unusually unfavorable terms of trade which followed the outbreak of the Korean War.

3) The 4 per cent acceptable growth rate has been applied cumulatively from 1953 . It would probably be more reasonable to assume an acceptable rate of slightly above 3 per cent from 1953 to 1963 and a 4 per cent rate thereafter. The "compromise" figures of columns (3) and (6) provide an estimate of this.

In addition, the 4 per cent growth rate implies a rate of increase in productivity greater than Britain actually experienced. On the usual assumptions about the cost/price process in the United Kingdom, this would imply a somewhat slower rise in domestic prices/cost than actually occurred. Hence,

13Full details of the data, assumptions and calculations on which this section is based are available on request from Professor David $C$. Rowan, University of Southampton, Southampton, England. 
real exports (which we have taken as exogenous) might be expected to be larger and real imports smaller than Table II suggests.

It seems, therefore, reasonable to argue that the calculated fundamental deficits for the years 1953.57 are probably overestimates, and that the calculations for the 4 per cent growth rates are also overestimates.

Despite these limitations, it seems a reasonable inference from Table II that the United Kingdom was probably in fundamental deficit by 1959 , if not by 1958. Moreover, the estimates suggest that from 1959 onwards the fundamental deficit grew very considerably. Finally, it is reasonable to assume that by 1967 the fundamental deficit was between $\& 1160$ million (which is certainly an overestimate) and $£ 410$ million (which is very probably an underestimate) with a reasonable guess putting it around $£ 750$ million.

As we have seen, no great claims can be made for this simple forecasting calculation. Other more refined and possibly more reliable forecasting techniques could doubtless be devised. Nevertheless, unless the calculations can display a very significant bias, they do suggest that the United Kingdom, during the period 1960-67, was suffering from a fundamental disequilibrium sufficiently large to be identified, with some confidence, by rather crude techniques.
Finally, in Table III we give the observed current account deficit taken from the official figures, and the fundamental current account deficits calculated for each "acceptable growth rate."

Extensive comment on Table III is unnecessary. It does, however, serve to show how poor a guide to long-run exchange policy the observed current balance may be. For example, the very substantial observed surplus in 1958, amounting to 2344 million, was, on even a 3 per cent growth basis, due very largely to the low level of economic activity. Nevertheless, there can be little doubt that this largely illusory observed surplus was an important factor in the British expansion of $1959-60$ and the Conservative electoral victory of 1959 .

Again the much smaller observed surpluses of 1962 and 1963 were due primarily to slow growth and increased unemployment. Nevertheless they were undoubtedly factors which encouraged the British expansion of 1963-64 and the very substantial deficit of 1964 .

Finally, it should also be clear that the observed deficits frequently overstate the fundamental deficits. They mislead, in fact, in much the same way as do the observed surpluses.

Though the arguments in this section can be no better than the simple regression model underlying

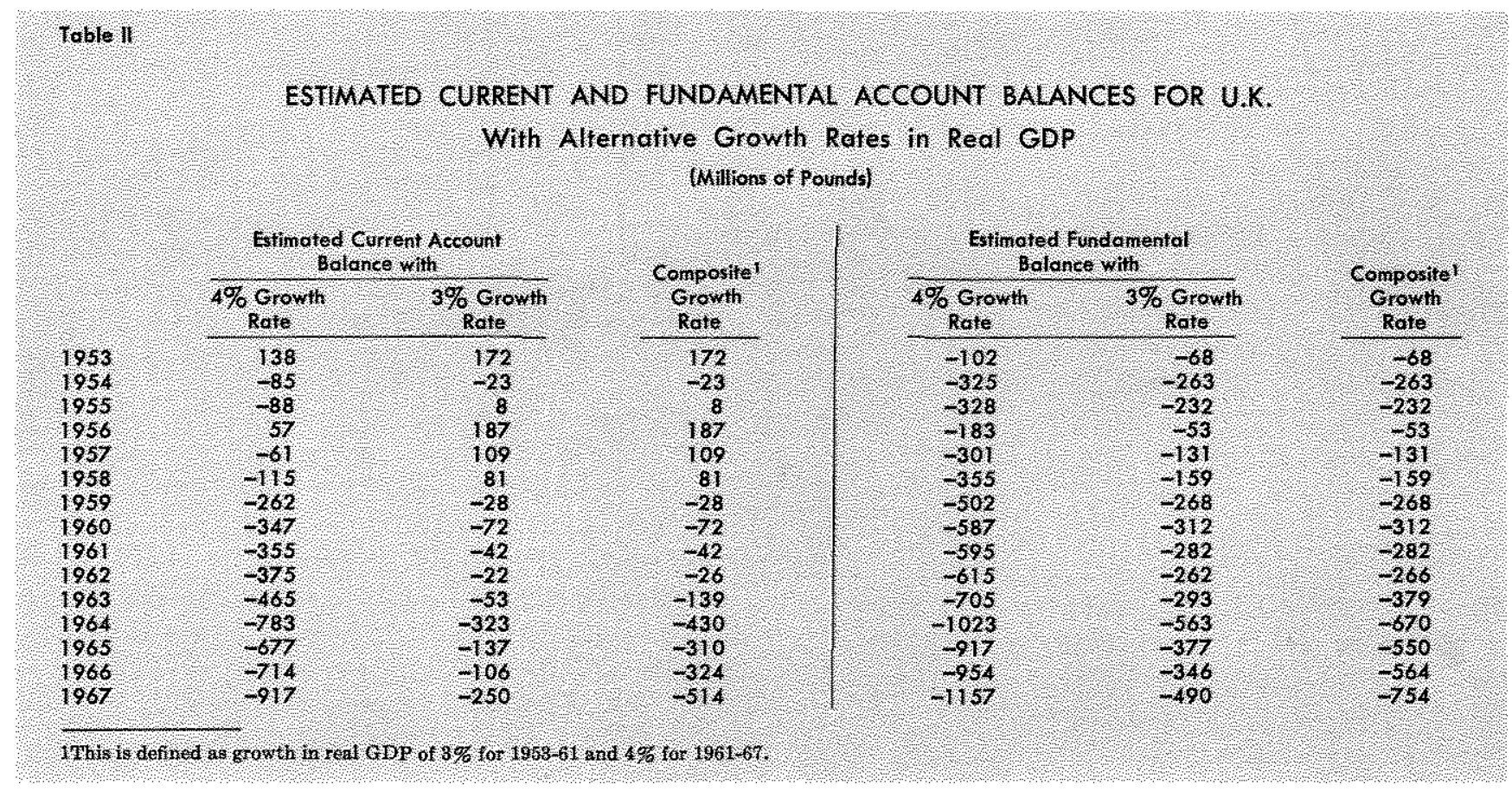




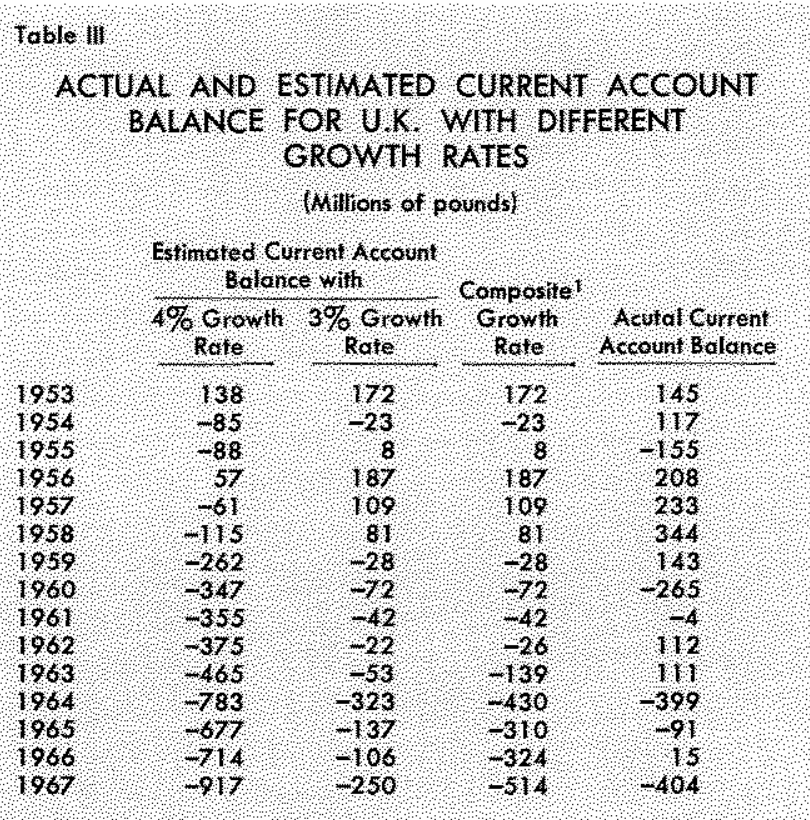

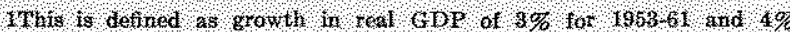
for 196167 ,

our calculations, it does not seem an overly strong position to adopt that:

1) there is evidence that considerably before 1967, and possibly as early as 1958, the United Kingdom was suffering from an identifiable fundamental disequilibrium;

2) in the absence of any other well-specified method of adjustment, devaluation came between nine and seven years later than was required; and

3) the observed current balance is an unreliable indicator of the fundamental current position.

\section{The General Applicability of British Experience}

This paper has argued that British exchange policy during the Sixties was misguided in that it sought to retain an external value of the pound incompatible with fundamental equilibrium. Moreover, we have suggested that the existence of a significant fundamental disequilibrium was identifiable many years before the pound was reluctantly devalued in November 1967.

We have also argued that the decision to retain a disequilibrium parity at the cost of slower growth and periods of reduced economic activity came, in the main, from a misreading of the events of the Thirties, and involved an implicit denial of the theory of internal adjustment. In place of this theory, no new analysis was developed. Instead, a variety of poorly specified solutions were canvassed. These culminated in the argument commonly used to defend the 1963-64 expansion; that is, if the United Kingdom expanded demand and output faster, then, after an initial period of external deficit to be financed by borrowing, the balance of payments would, in some way not clearly specified, attain equilibrium. After the exposure of this panacea in 1964, Britain was virtually without a long-run external policy until 1967.

It is also the case that, though the British experience has been the most dramatic, the reluctance of the British authorities to alter a disequilibrium exchange rate has its counterparts elsewhere. At the moment of writing, the German authorities are refusing to revalue a probably undervalued mark, and the French authorities are refusing to devalue a probably overvalued franc. It has also been suggested in some quarters that the dollar itself is overvalued. Thus the attitude of the British authorities, though not the experience of the British economy, is far from atypical. National governments and monetary authorities, or so at least it seems, are reluctant to undertake planned exchange adjustments. Since exchange adjustments ultimately cannot be avoided, the outcome has been that crucial adjustments, because they have been unnecessarily delayed, have been unnecessarily large. Moreover, most adjustments have been undertaken only when national monetary authorities have been compelled, usually by speculators, to recognize the inevitable. As a result, the international monetary system created at Bretton Woods has, on a number of occasions, been brought close to collapse.

The system established at Bretton Woods reffected, though admittedly imperfectly, the Keynesian concept of managed flexibility of exchange rates. Under the Bretton Woods arrangements, limited changes in parities (defined as less than 10 per cent of the parities existing in 1944) could be made unilaterally. It was also envisaged that countries in fundamental deficit would adjust their exchange rates by international agreement, thus avoiding competitive devaluations like those of the Thirties. Finally, a country in chronic "fundamental surplus" which was unwilling to appreciate could have its currency declared "scarce" - a declaration which permitted its trading partners to discriminate against it.

Unfortunately, the system has never been allowed to operate as the theory on which it was based required. The principal reason for this has been the 
attachment of central bankers and financial communities to rigid parities.

It is, however, doubtful whether central bankers, even if disposed to favor exchange adjustments, could always persuade their governments to take such actions. Politicians and even financiers seem to attach national prestige to particular parities, and many persons who are not central bankers seem to regard an external surplus as a sign of economic virtue and a deficit as a sign of economic vice.

Furthermore, it should not be forgotten that central bankers usually attach considerable (and not necessarily excessive) importance to price stability. A regime of fixed exchange rates tends to insure that a domestic inflation is accompanied by an external deficit. To this extent it increases the ability of central bankers to urge deflation. Unfortunately, the concurrence of domestic inflations and external deficits has, in some cases, encouraged central bankers to diagnose fundamental deficits which are structural in origin as due to macroeconomic mismanagement, and thus to urge deflation rather than exchange adjustment. ${ }^{1}$ It is, indeed, hard to escape the impression that many of the international gatherings of central bankers at Basle and elsewhere are necessitated by the need to find temporary solutions to problems created by their own attachment to exchange rigidity rather than by the alleged refusal of deficit countries to deflate sufficiently.

The result has been that, instead of the managed flexibility with relatively small but frequent adjustments which Bretton Woods required, we have had the worst of all possible worlds - large, infrequent and usually long-delayed exchange changes as well as periods of considerable uncertainty and speculation. The present problems of the mark and the franc (and possibly the dollar and the pound) reflect the inability of the central bankers and international mon. etary authorities to accept the need for smaller and more frequent exchange adjustments.

\section{Towards A Rational Exchange Policy}

The British experience is valuable not only because it emphasizes the incompatibility of rigid exchange rates and domestic economic objectives, but also because it suggests the length of time which

\footnotetext{
14For an example of this position together with an optinistic assessment of the ability of the monetary authority to distinguish between external imbalances due to macroeconomic mismanagement and structural maladjustment, see Otmar Emminger, "Practical Aspects of the Problem of Balance of Payments Adjustments, Journal of Political Economy, August 1967.
}

may have to elapse before a national monetary authority can be persuaded to face this incompatibility. Inevitably this strengthens the case for some form of exchange flexibility. Theoretically there is a powerful case for permitting the rates of the principal developed countries to float, and experience with floating rates, in Britain after 1931 and in Canada from 1950 to 1962 , does not destroy this case. In practice, however, primarily because of the attitudes of central bankers and financial communities, it may be wiser to aim at a system which permits countries to change their rates by a small percentage each year (the "crawling peg"), 1 ,

From the present system it should be possible to move to the "crawling peg" system and finally to floating rates. This evolutionary approach should have the merits of encouraging the appropriate development of a forward market in foreign exchange and, by giving experience with continuous but small adjustment, removing some of the exaggerated fears of exchange flexibility.

In advocating development along these flexible lines, three points need to be made clear.

1) Limited Alexibility is less likely to work well if it is introduced into a system in which some key countries are in marked fundamental disequilibrium as they probably are at present. It may be necessary, therefore, to begin with an agreed realignment of key rates based upon the best estimates which can be made of the equilibmium rates.

2) Limited flexibility should be viewed as a stage in the movement towards fully floating rates not as a means of establishing parities which can subsequently be pegged.

3) It must be realized that limited flexibility, whether based upon discretionary or automatic adjustment, is not a panacea. It will not eliminate temporary crises, movements of "hot" money arising out of the capacity of financial communities to frighten themselves, or the need for reserves.

Limited flexibility, therefore, should be seen as a "second-best" choice preferable to the present system because it offers a means of bringing about relatively smoother movements in the exchange rate, and thus is a way of eliminating the lengthy tragedy of errors which appears to have been the British experience from 1960.

15 McKenzie, pp. $55-23$, presents a fuller review of the "crawling peg."

This article is available as Reprint No. 38. 